\title{
Caries Preventive and Antibacterial Effects of Two Natural Mouthwashes vs Chlorhexidine in High Caries-risk Patients: A Randomized Clinical Trial
}

\author{
Dina Kamal ${ }^{1}$, Hassan Hassanein ${ }^{2}$, Mai Akah ${ }^{3}$, Mostafa A Abdelkawy ${ }^{4}$, Heba Hamza ${ }^{5}$
}

\begin{abstract}
Aim and objective: To evaluate the caries preventive and antibacterial effects of Gum Arabic and Licorice mouthwashes vs chlorhexidine in high caries-risk patients. The prevalence of oral side effects from using the mouthwashes was also assessed.

Materials and methods: Total 63 participants categorized as high caries-risk according to the CAMBRA caries-risk model were recruited. They were randomly allocated to three groups ( $n=21$ ) according to the mouthwash used: G1 (Gum Arabic), G2 (Licorice), and G3 (Chlorhexidine). Baseline DMF scores and saliva samples were obtained. DMF scores, salivary Streptococcus mutans (SM) and Lactobacillus acidophilus (LA) counts, and any reported oral side effects were recorded after 3,6, 9, and 12 months. The obtained results were subjected to the statistical analysis and the significance level was set at $p \leq 0.05$.

Results: Regarding DMF scores, no statistically significant difference was found between the three groups at baseline, after 3, 6, and 9 months. After 12 months, a statistically significant difference was found between G3 and each of G1 and G2 where G3 showed significantly higher DMF scores $(p<0.001)$. No statistically significant difference was found between G1 and G2. Regarding antibacterial activity, after 6 months, all mouthwashes showed statistically significant antibacterial effect against SM and LA with no statistically significant difference between them $(p<0.001)$. After 9 and 12 months, G1 and G2 showed a statistically significant reduction in SM and LA counts $(p<0.001)$. However, G3 showed a statistically significant increase in SM and LA counts indicating bacterial resistance $(p<0.001)$. No oral side effects were reported in G1 and G2. On the other hand, several oral side effects were reported in G3.

Conclusion: Gum Arabic and Licorice mouthwashes show promising caries preventive and antibacterial effects with no oral side effects reported. Clinical significance: Natural mouthwashes can serve as substitutes to chemical agents as chlorhexidine, providing effective caries control and safe long-term use.

Keywords: Antibacterial effect, Caries preventive effect, Gum Arabic, Licorice, Natural mouthwashes, Oral side effects, Randomized clinical trial. The Journal of Contemporary Dental Practice (2020): 10.5005/jp-journals-10024-2986
\end{abstract}

\section{INTRODUCTION}

Dental caries is the most challenging oral disease seen in the dental practice and continues to be a major health concern. Dental caries is caused by specific acid-producing bacteria that ferment dietary carbohydrates leading to demineralization and destruction of the dental hard tissue. ${ }^{1}$

By understanding the nature of the disease, being a dynamic process of alternating periods of demineralization and remineralization, best controlled by minimizing the risk factors and maximizing the protective factors, caries is now defined as a disease that is reversible and preventable. ${ }^{2}$

Research in the field of caries prevention has entailed that one of the main goals is to reduce or totally eliminate cariogenic bacteria as they are a major etiological factor especially in high caries-risk patients. ${ }^{3}$ As the oral environment shifts to a favorable ecology for these cariogenic bacteria, it will result in a high bacterial count in saliva, which also correlates to a high count in the dental plaque. ${ }^{4}$ Patients with high bacterial counts in saliva up to $\geq 10^{6} \mathrm{CFU} / \mathrm{mL}$ are susceptible to an extremely high incidence of developing future caries. $^{5}$

Antimicrobials have been widely used against cariogenic bacteria for effective caries control. Many chemoprophylactic agents are used in adjunct to mechanical oral hygiene measures and are most delivered in the form of mouthwashes. ${ }^{6}$
${ }_{1,3,5}$ Conservative Dentistry Department, Faculty of Dentistry, Cairo
University, Cairo, Egypt
${ }^{2}$ Dentistry Department, Heidelberg University, Heidelberg, Germany
${ }^{4}$ Pharmacognosy Department, Faculty of Pharmacy, Cairo University,
Cairo, Egypt
Corresponding Author: Dina Kamal, Conservative Dentistry Department, Faculty of Dentistry, Cairo University, Cairo, Egypt, Phone: +20 02 23634965, e-mail: dina.kamal@dentistry.cu.edu.eg

How to cite this article: Kamal D, Hassanein H, Akah M, et al. Caries Preventive and Antibacterial Effects of Two Natural Mouthwashes vs Chlorhexidine in High Caries-Risk Patients: A Randomized Clinical Trial. J Contemp Dent Pract 2020;21(12):1316-1324.

Source of support: Nil

Conflict of interest: None

Chlorhexidine is a chemical antimicrobial that has been used for decades and is considered the gold standard of oral preventive therapy. ${ }^{7}$ However, the use of chlorhexidine has led to several undesirable side effects such as burning sensation, altered taste, metallic taste, and staining of teeth or restorations. ${ }^{8}$

Thus, the need for an alternative antimicrobial agent that is both effective and can be used daily with no side effects is of a great concern. This has led to an increased interest in natural herbal

( ) Jaypee Brothers Medical Publishers. 2020 Open Access This article is distributed under the terms of the Creative Commons Attribution 4.0 International License (https://creativecommons.org/licenses/by-nc/4.0/), which permits unrestricted use, distribution, and non-commercial reproduction in any medium, provided you give appropriate credit to the original author(s) and the source, provide a link to the Creative Commons license, and indicate if changes were made. The Creative Commons Public Domain Dedication waiver (http://creativecommons.org/publicdomain/zero/1.0/) applies to the data made available in this article, unless otherwise stated. 
therapeutic remedies as substitutes, providing effective anti-caries activity and safe long-term use. ${ }^{9}$

Medicinal herbal plant formulations offer many advantages such as low cost, ease of availability, and a nontoxic profile. ${ }^{9}$ Considering their several useful pharmacological actions such as antimicrobial, anti-inflammatory, soothing, and healing properties, their use for the prevention of caries and oral diseases seems beneficial. $^{10}$

Acacia gum, also known as Gum Arabic, is a traditional plant with medicinal properties effective in wound healing, analgesia, hemostasis, and antibacterial properties. It was generally used for treating gingivitis and mouth ulcers. ${ }^{11}$ It has also been confirmed to possess anti-cariogenic effect against Streptococcus mutans..$^{11-13}$

Glycyrrhiza glabra, commonly known as Licorice, is one of the important traditional medicinal plants used by many cultures to relieve coughs, sore throats, and gastric inflammation. ${ }^{7}$ Its anticariogenic, soothing, anti-inflammatory, and anticancer properties have potential benefits to prevent caries and oral diseases. ${ }^{5}$

Due to the lack of sufficient clinical evidence on the ability of Gum Arabic and Licorice to prevent caries and reduce cariogenic bacteria, this randomized controlled clinical trial was conducted to evaluate the effect of Gum Arabic and Licorice mouthwashes on caries prevention and reduction of cariogenic bacteria compared to chlorhexidine mouthwash in high caries-risk patients. The frequency of the reported oral side effects from using these three mouthwashes was also assessed.

\section{Materials and Methods}

\section{Study Design}

This three-arm parallel, triple-blind, randomized, 12-month clinical trial was held in the outpatient clinic of the Conservative Dentistry Department-Faculty of Dentistry, Cairo University, from October 2018 to January 2020. It was approved by the Research Ethics Committee (REC)—Faculty of Dentistry, Cairo University. A total of 63 participants were selected for this study, randomly allocated to three groups $(n=21)$ according to the mouthwash used, where group 1: $6.25 \%$ Gum Arabic mouthwash, group 2: $12.5 \%$ Licorice mouthwash, and group 3: 0.12\% Chlorhexidine mouthwash.

\section{Sample Size Calculation}

Based on a previous study ${ }^{14}$ with the power of test set at 80 and $5 \%$ significance level, the estimated sample size was 16 participants per group. This number was increased to 21 participants per group to compensate for any losses during follow-up. A total of 63 participants $(n=21)$ were enrolled in this study.

\section{Eligibility Criteria}

The inclusion criteria for entering the study were as follows: male or female participants aged from 18 to 35 years; participants categorized as high caries-risk according to the CAMBRA caries risk model; baseline of at least two to three active noncavitated or cavitated carious lesions; baseline DMF score of at least 3-5; baseline salivary Streptococcus mutans count $\geq 10^{6} \mathrm{CFU} / \mathrm{mL}$; baseline salivary Lactobacillus acidophilus count $\geq 10^{4} \mathrm{CFU} / \mathrm{mL}$; and cooperative patients approving to participate in the study. ${ }^{1,15}$

The exclusion criteria were as follows: any systemic conditions or severe medical complications; current medications that may affect the oral flora or salivary flow; allergy to any of the ingredients of the study products; use of any antibiotics within the past 3 months; use of any mouth rinses within the past 3 months; current periodontitis (sites of probing pocket depth $\geq 5 \mathrm{~mm}$ ); presence of developmental dental anomalies; presence of orthodontic appliance or removable prosthesis; pregnancy; xerostomia; heavy smoking; alcohol or drugs addiction; or any conditions that may decrease adhering to the study. ${ }^{16,17}$

\section{Randomization, Sequence Generation, and Allocation Concealment}

Total 63 eligible participants (mean age $=29.61 \pm 4.51$, 39 females, 24 males) were randomly allocated to the three groups through an online randomization Web-based tool (https://www.random. org/). Generated random numbers were placed in opaque sealed envelopes prepared by a contributor who was not involved in the study and the allocation sequence was concealed from the primary investigator. Total 63 participants completed the study (Flowchart 1, CONSORT 2010 Flow Diagram).

\section{Study Participants}

Comprehensive personal, medical, and dental histories were obtained from each participant and registered in their dental charts. All participants received information about the study, its aim, procedures, safety precautions, benefits, and the expected duration of participation. Afterward, an informed consent containing all the ethical aspects of the trial was signed by the eligible participants.

Oral hygiene measures were emphasized, and motivation was done to all participants. Prophylactic scaling and polishing were done. All dental complaints were managed before the commencement of the study. Participants were encouraged to brush their teeth daily. They were given instructions on how to use a soft toothbrush with toothpaste, the proper brushing technique, and dental flossing to maintain regular oral hygiene. At each follow-up visit, the primary investigator ensured that participants performed and maintained oral hygiene. An agreement was made not to use any other oral hygiene products than those assigned during the study. ${ }^{18}$

\section{Clinical Examination and DMF Scoring Index}

Two examiners who were blinded to the participants' assigned groups performed the clinical examination. Dental caries was assessed according to the International Caries Detection and Assessment System "ICDAS II" using a dental mirror and a 0.5- $\mathrm{mm}$ ball-ended CPI probe (CPITN Probe, Premium Instruments, New York, USA). ${ }^{9}$ The examiners were trained and calibrated to record the caries status through an e-learning program available on the International Caries Classification and Management System "ICCMS" website, specifically designed for the training and calibration of ICDAS - by explaining the examination protocol and reviewing the coding system. ${ }^{19}$ In addition, a random selection of $10 \%$ of the participants were reexamined at baseline and follow-up examinations to determine the examiners' repeatability. ${ }^{20}$ In case of disagreements, the teeth were reexamined, and consensus reached among the examiners. The teeth were examined after they were properly cleaned and dried, with adequate light and magnification. The CPI probe was used with negligible pressure to avoid any damage to the tooth surface. ${ }^{21}$

Caries diagnosed by visual inspection and tactile examination was not confirmed by dental radiographs. Dental radiographs were only taken when further investigations were needed. ${ }^{22} \mathrm{~A}$ baseline DMF score was obtained for each participant and recorded in their dental chart. DMF was carried out by counting the number of decayed, filled, or missed teeth. Missing teeth were recorded 
Flowchart 1: CONSORT 2010 Flow Diagram

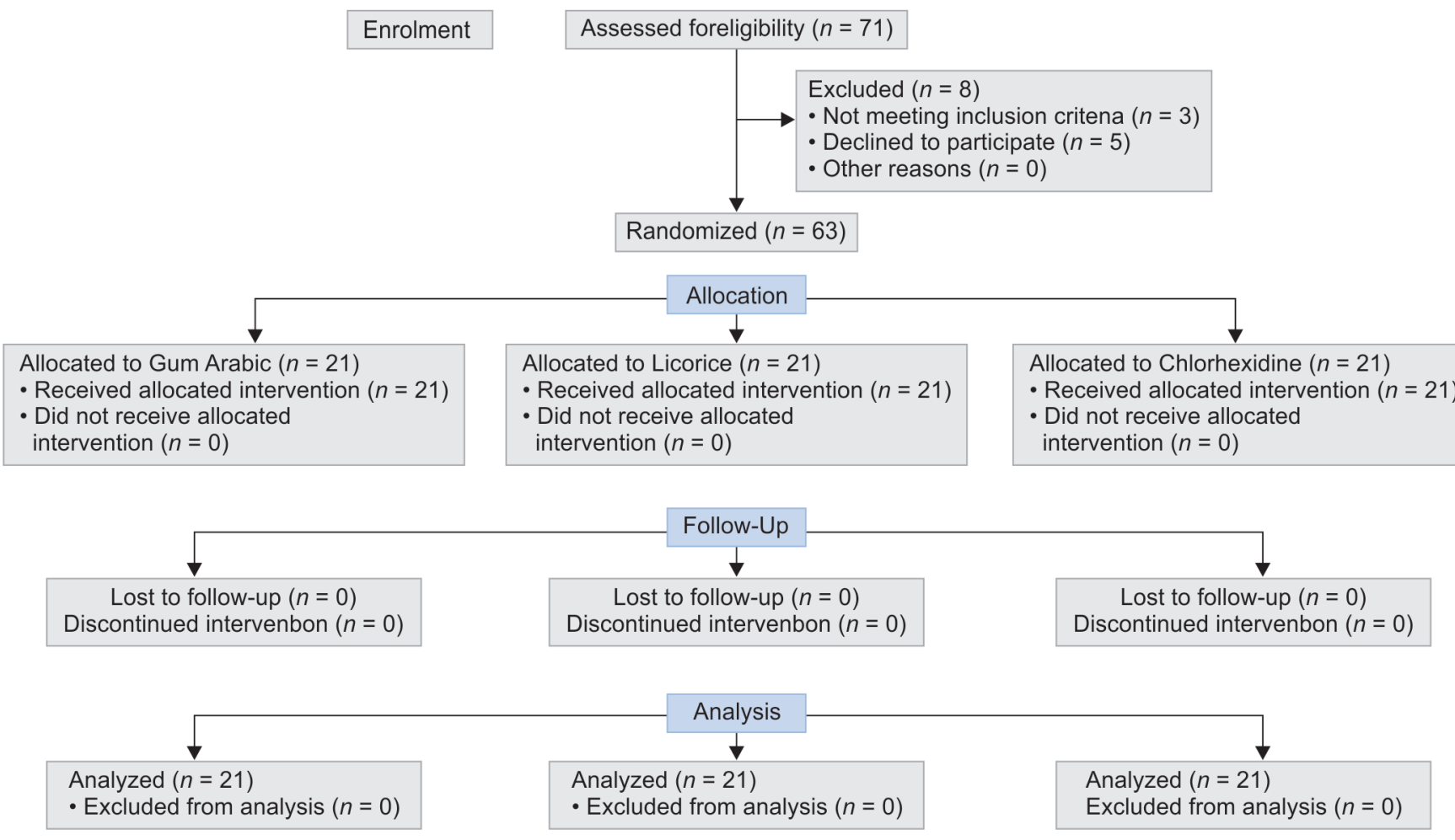

only if they were extracted due to caries. All participants received caries removal and restorations following the baseline examination. Participants with any carious lesion developed during the study received the suitable dental treatment. ${ }^{9,22}$

\section{Preparation of Crude Extracts}

Gum Arabic (Acacia senegal) powder and Licorice (Glycyrrhiza glabra) powder were obtained from a local market of medicinal herbs. They were identified and authenticated in the Botany DepartmentFaculty of Science, Cairo University, Egypt. The crude extract of each plant was prepared in the Pharmacognosy Department-Faculty of Pharmacy, Cairo University, Egypt. The extraction process was carried out through maceration. The powder of each plant was soaked in $70 \%$ ethanol $(1: 10 \mathrm{w} / \mathrm{v})$ for 3 days with intermittent shaking to leach out the active ingredients into the solvent. Afterward, the attained solution was filtered using muslin cloth to remove any residues. It was filtered again using grade I Whatman filter paper. The filtered solution was concentrated in vacuum at $40^{\circ} \mathrm{C}$ using a rotary evaporator (Rotavapor R-114, BÜCHI Labortechnik AG, Flawil, Switzerland) until a solid layer of the plant extract was obtained. The solid plant extract was lyophilized (Alpha 3-4 LSCbasic Martin Christ freeze-dryer, Osterode, Germany), then finely ground, and stored at $4^{\circ} \mathrm{C}$ in a tightly closed container to preserve it from any contamination, deterioration, or decomposition until further use. ${ }^{9,23}$

\section{Determination of Minimum Inhibitory Concentration}

The minimum inhibitory concentration (MIC) of the crude plant extracts against Streptococcus mutans and Lactobacillus acidophilus was determined by the broth tube dilution method in accordance with the National Committee for Clinical Laboratory Standards (NCCLS) guidelines. A series of twofold dilution of each extract ranging from 500 to $0.9 \mathrm{mg} / \mathrm{mL}$ was made in the Muller Hinton broth. Total $100 \mu \mathrm{L}$ of standard inoculum of the bacterial strain matched to $0.5 \mathrm{Mc}$ Farland's standard $\left(1.5 \times 10^{8} \mathrm{CFU} / \mathrm{mL}\right)$ was seeded into each dilution. Two control tubes were also performed, the tube with no bacteria (extract and growth media only) represented the positive control, while the tube without the extract (bacteria and growth media only) represented the negative control. All test tubes were incubated at $37^{\circ} \mathrm{C}$ in the presence of $5 \% \mathrm{CO}_{2}$ for 24 hours. After incubation, the tubes were checked for turbidity, which denotes bacterial growth. Minimum inhibitory concentration was determined as the highest dilution (the lowest concentration) of the extract that showed no visible bacterial growth (no turbidity). ${ }^{24,25}$

\section{Determination of Minimum Bactericidal Concentration}

The minimum bactericidal concentration $(\mathrm{MBC})$ was determined by selecting the tubes that showed no bacterial growth during the MIC determination. Total $10 \mu \mathrm{L}$ from each tube was subcultured on Mueller-Hinton agar plates and further incubated at $37^{\circ} \mathrm{C}$ for 24 hours. After incubation, MBC was defined as the lowest concentration at which no bacterial growth (no colonies) was observed on the agar plate. ${ }^{26}$

The potential cytotoxicity of different concentrations of crude extracts of both plants has been previously investigated by several studies. ${ }^{7,27-29}$ They reported that no cytotoxicity was observed and confirmed that both Gum Arabic and Licorice extracts are safe and nontoxic.

\section{Preparation of Mouthwashes}

According to the MBC, $62.5 \mathrm{mg}$ of the Gum Arabic crude extract powder was weighed on a digital scale and dissolved in $1 \mathrm{~mL}$ distilled water. In this way, a $6.25 \%$ concentration Gum Arabic mouthwash was formulated. The same was done where $125 \mathrm{mg}$ of the Licorice crude extract powder was dissolved in $1 \mathrm{~mL}$ distilled water to formulate a $12.5 \%$ concentration Licorice mouthwash. ${ }^{30}$ Each mouthwash was transferred to opaque glass bottles, labeled 
with nonidentifiable numbers by a contributor to ensure blinding of the primary investigator and participants. Each bottle contained the needed amount for 1-week use. At each month, the bottles were refilled with a freshly prepared mouthwash to use for another week.

\section{Instructions for Mouthwash Use}

Participants were instructed to rinse with $10 \mathrm{~mL}$ of mouthwash for 1 minute, once daily for 1 week of each month. This regimen was repeated monthly for a period of 1 year. ${ }^{1}$ The participants were advised to swirl the mouthwash from one side to the center, to the other side of the mouth and then back again in a continuous, slow manner. They were instructed to swirl the mouthwash to the front of the mouth as well, ensuring all the oral cavity is exposed. They were instructed not to rinse with water afterward. They were also instructed to refrain from eating or drinking for 1 hour after using the mouthwash. The participants were informed to store the mouthwash bottle in the refrigerator. ${ }^{9}$

\section{Saliva Sample Collection}

About $2 \mathrm{~mL}$ of unstimulated saliva samples were collected in a sterile sealed test tube by asking the participants to passively drool for 5 minutes, seated in an upright position. Saliva samples were collected in the morning to avoid any bias in the concentration of saliva due to circadian rhythm. ${ }^{10}$ Participants were asked not to eat or drink anything (except water) 1 hour before saliva collection to minimize the possible food debris and stimulation of saliva. ${ }^{31}$ Saliva samples were obtained at baseline, after 3, 6, 9, and 12 months. The test tubes containing the saliva samples were transported immediately to the Microbiology Department-Cairo University for the microbial analysis. The tubes were labeled with nonidentifiable numbers to ensure blinding of the microbiologist.

\section{Microbial Analysis}

Saliva samples were homogenized for 2 minutes by a vortex mixer (Assistent Reamix 2789 Vortex Mixer, Medical Trade Center, Hamburg, Germany). A serial dilution was generated, where $1 \mathrm{~mL}$ of the homogenate saliva was added to a tube containing $9 \mathrm{~mL}$ of sterile phosphate buffer saline ( $\mathrm{pH} 7.0)$ to give a tenfold (1:10 or $10^{1}$ ) dilution. This sample was further serially diluted by taking 1 $\mathrm{mL}$ and adding it to a second tube containing $9 \mathrm{~mL}$ of sterile saline, obtaining $10^{2}$ dilution. Serial dilution was continued by repeating the same procedure to obtain $10^{3}$ and $10^{4}$ dilutions. ${ }^{31}$

Mitis Salivarius Agar and Lactobacillus MRS Agar (HiMedia Laboratories Pvt. Ltd, Mumbai, India) were used as culture media for the isolation of total salivary Streptococcus mutans and Lactobacillus acidophilus counts, respectively. Appropriate amounts of each semisolid media were poured onto petri plates and allowed to solidify at room temperature. ${ }^{32}$ From the $10^{4}$ dilution, $0.1 \mathrm{~mL}$ was taken using a micropipette and was streaked evenly on the surface of the agar using a sterile glass spreader to give homogeneous bacterial growth. ${ }^{33}$

The Mitis Salivarius Agar plates were placed in a microaerophilic environment $\left(5-10 \% \mathrm{CO}_{2}\right)$ created by using a candle jar and incubated at $37^{\circ} \mathrm{C}$ for 48 hours. ${ }^{34}$ The MRS plates were placed in an anaerobic environment using a Gas-Pak jar and an anaerobic gas-generating system (AnaeroGenTM, Thermo Fisher Scientific Inc., Massachusetts, USA), properly sealed and incubated at $37^{\circ} \mathrm{C}$ for 48 hours. ${ }^{35}$ Colony counting was done under a colony counter and the number of colonies were multiplied by the dilution factor of the plate counted and expressed as colony-forming units per milliliter (CFU/mL) of saliva. ${ }^{32}$

\section{Recording Oral Side Effects}

A compliance diary was given to each participant. They were asked to make an entry of each usage and to record any experienced oral side effects. During each follow-up visit, they were once more asked about the side effects that might have occurred during or after the mouthwash use and were recorded in a checklist. ${ }^{36}$ The oral side effects included pain, burning sensation, pruritus (itchiness), soft tissue irritation (desquamation, ulcer), taste disturbance (altered taste perception), metallic taste, dryness of mouth, discoloration of tooth/tongue surfaces, numbness, and parotid gland swelling. ${ }^{37}$

\section{Outcomes}

The primary outcome of this study was the increment in the number of decayed, missed, and filled teeth (DMF scores) from baseline till after 3, 6, 9, and 12 months follow-up. The secondary outcome was the antibacterial effect of the mouthwashes on Streptococcus mutans and Lactobacillus acidophilus measured by the difference in CFU/mL count from baseline and after each follow-up. The tertiary outcome was oral side effects reported from using the mouthwashes. DMF scores, saliva sample collection, and side effects obtained were done by assessors blinded to the participants' assigned groups.

\section{Statistical Analysis}

Statistical analysis was performed with the IBM SPSS (version 20) software (SPSS Inc., IBM Corporation, NY, USA). The significance level was set at $p \leq 0.05$. Antibacterial effect data were analyzed using one-way ANOVA followed by the Tukey post hoc test to compare between more than two groups. Repeated measure ANOVA was used to compare between more than two groups in related samples. The paired sample $t$-test was used to compare between two groups. Two-way ANOVA was used to test the interaction between variables. Caries preventive effect data were analyzed using the Kruskal-Wallis test to compare between more than two groups. The Mann-Whitney test was used to compare between two groups. Friedman was used to compare between more than two groups in related samples. Wilcoxon was used to compare between two groups. Categorical data of reported side effects were presented as frequencies ( $n$ ) and percentages (\%).

\section{Results}

\section{Caries Preventive Effect}

Table 1 represents the mean and standard deviation of DMF scores of the three groups at different time intervals. There was no statistically significant difference between the three mouthwashes at baseline, after 3, 6, and 9 months ( $p>0.05)$. After 12 months, a statistically significant difference was found between $\mathrm{G} 3$ and each of $\mathrm{G} 1$ and $\mathrm{G} 2(p<0.05)$. No statistically significant difference was found between $\mathrm{G} 1$ and $\mathrm{G} 2$ ( $p>0.05)$.

\section{Antibacterial Effect}

Tables 2 and 3 represent the mean and standard deviation of Streptococcus mutans and Lactobacillus acidophilus colony counts of the three groups at different time intervals, respectively. There was a significant reduction in colony counts after 3 and 6 months $(p<0.05)$. No statistically significant difference was found between the three mouthwashes at baseline, after 3 and 6 months $(p>0.05)$. However, after 9 and 12 months, there was a statistically significant difference between the three groups ( $p<0.05)$. A statistically significant difference was found between $G 1$ and each of $G 2$ and 
Caries Preventive Effect of Gum Arabic and Licorice Mouthwashes

Table 1: Mean \pm SD of DMF scores of all tested groups at different time intervals

\begin{tabular}{|c|c|c|c|c|c|c|c|}
\hline \multirow[b]{3}{*}{ Variables } & \multicolumn{7}{|c|}{ DMF scores } \\
\hline & \multicolumn{2}{|c|}{ G1 (Gum Arabic) } & \multicolumn{2}{|c|}{ G2 (Licorice) } & \multicolumn{2}{|c|}{ G3 (Chlorhexidine) } & \multirow[b]{2}{*}{$p$ value } \\
\hline & Mean & $S D$ & Mean & $S D$ & Mean & $S D$ & \\
\hline Baseline & $8.05^{a, B}$ & 1.20 & $7.95^{\mathrm{a}, \mathrm{B}}$ & 1.50 & $8.52^{\mathrm{a}, \mathrm{C}}$ & 1.17 & $0.382 \mathrm{~ns}$ \\
\hline 3 months & $8.05^{\mathrm{a}, \mathrm{B}}$ & 1.20 & $7.95^{\mathrm{a}, \mathrm{B}}$ & 1.50 & $8.52^{\mathrm{a}, \mathrm{c}}$ & 1.17 & $0.382 \mathrm{~ns}$ \\
\hline 6 months & $8.05^{a, B}$ & 1.20 & $8.00^{\mathrm{a}, \mathrm{B}}$ & 1.52 & $8.57^{a, c}$ & 1.12 & $0.344 \mathrm{~ns}$ \\
\hline 9 months & $8.14^{\mathrm{a}, \mathrm{B}}$ & 1.11 & $8.05^{\mathrm{a}, \mathrm{B}}$ & 1.53 & $8.81^{\mathrm{a}, \mathrm{B}}$ & 1.33 & $0.246 \mathrm{~ns}$ \\
\hline 12 months & $8.24^{\mathrm{b}, \mathrm{A}}$ & 1.22 & $8.19^{\mathrm{b}, \mathrm{A}}$ & 1.50 & $9.62^{\mathrm{a}, \mathrm{A}}$ & 1.28 & $0.003^{*}$ \\
\hline$p$ value & $0.012^{*}$ & $0.019^{*}$ & $<0.001 *$ & & & & \\
\hline
\end{tabular}

$\left(^{*}\right)$ : significant; (ns): nonsignificant. Statistical comparison between tested groups at $p \leq 0.05$. Different small-letter superscripts indicate statistically significant difference within the same row. Different capital-letter superscripts indicate statistically significant difference within the same column

Table 2: Mean \pm SD of Streptococcus mutans counts of all tested groups at different time intervals

\begin{tabular}{|c|c|c|c|c|c|c|c|}
\hline \multirow[b]{3}{*}{ Variables } & \multicolumn{7}{|c|}{ Streptococcus mutans $\left(\log _{10} \mathrm{CFU} / \mathrm{mL}\right)$} \\
\hline & \multicolumn{2}{|c|}{ G1 (Gum Arabic) } & \multicolumn{2}{|c|}{ G2 (Licorice) } & \multicolumn{2}{|c|}{ G3 (Chlorhexidine) } & \multirow[b]{2}{*}{$p$ value } \\
\hline & Mean & $S D$ & Mean & $S D$ & Mean & $S D$ & \\
\hline Baseline & $7.09^{\mathrm{a}, \mathrm{A}}$ & 0.13 & $7.02^{\mathrm{a}, \mathrm{A}}$ & 0.11 & $7.11^{\mathrm{a}, \mathrm{A}}$ & 0.11 & $0.390 \mathrm{~ns}$ \\
\hline 3 months & $6.88^{a, B}$ & 0.09 & $6.88^{\mathrm{a}, \mathrm{B}}$ & 0.09 & $6.82^{\mathrm{a}, \mathrm{D}}$ & 0.07 & $0.052 \mathrm{~ns}$ \\
\hline 6 months & $6.72^{\mathrm{a}, \mathrm{c}}$ & 0.11 & $6.78^{\mathrm{a}, \mathrm{c}}$ & 0.11 & $6.78^{\mathrm{a}, \mathrm{D}}$ & 0.13 & $0.209 \mathrm{~ns}$ \\
\hline 9 months & $6.44^{\mathrm{c}, \mathrm{D}}$ & 0.14 & $6.68^{b, D}$ & 0.11 & $6.99^{\mathrm{a}, \mathrm{c}}$ & 0.11 & $<0.001^{*}$ \\
\hline 12 months & $6.23^{\mathrm{C}, \mathrm{E}}$ & 0.22 & $6.58^{\mathrm{b}, \mathrm{E}}$ & 0.10 & $7.02^{\mathrm{a}, \mathrm{B}}$ & 0.09 & $<0.001^{*}$ \\
\hline$p$ value & $<0.001^{*}$ & $<0.001^{*}$ & $<0.001^{*}$ & & & & \\
\hline
\end{tabular}

$\left(^{*}\right)$ : significant; (ns): nonsignificant. Statistical comparison between tested groups at $p \leq 0.05$. Different small-letter superscripts indicate statistically significant difference within the same row. Different capital-letter superscripts indicate statistically significant difference within the same column

Table 3: Mean \pm SD of Lactobacillus acidophilus counts of all tested groups at different time intervals

\begin{tabular}{|c|c|c|c|c|c|c|c|}
\hline \multirow[b]{3}{*}{ Variables } & \multicolumn{7}{|c|}{ Lactobacillus acidophilus ( $\log _{10} \mathrm{CFU} / \mathrm{mL}$ ) } \\
\hline & \multicolumn{2}{|c|}{ G1 (Gum Arabic) } & \multicolumn{2}{|c|}{ G2 (Licorice) } & \multicolumn{2}{|c|}{ G3 (Chlorhexidine) } & \multirow[b]{2}{*}{$p$ value } \\
\hline & Mean & $S D$ & Mean & $S D$ & Mean & $S D$ & \\
\hline Baseline & $6.88^{\mathrm{a}, \mathrm{A}}$ & 0.10 & $6.88^{\mathrm{a}, \mathrm{A}}$ & 0.09 & $6.83^{\mathrm{a}, \mathrm{A}}$ & 0.12 & $0.212 \mathrm{~ns}$ \\
\hline 3 months & $6.64^{\mathrm{a}, \mathrm{B}}$ & 0.13 & $6.71^{\mathrm{a}, \mathrm{B}}$ & 0.11 & $6.59^{\mathrm{a}, \mathrm{C}}$ & 0.19 & $0.050 \mathrm{~ns}$ \\
\hline 6 months & $6.50^{\mathrm{a}, \mathrm{c}}$ & 0.14 & $6.61^{\mathrm{a}, \mathrm{c}}$ & 0.13 & $6.57^{\mathrm{a}, \mathrm{c}}$ & 0.21 & $0.087 \mathrm{~ns}$ \\
\hline 9 months & $6.30^{c, D}$ & 0.14 & $6.52^{\mathrm{b}, \mathrm{D}}$ & 0.17 & $6.70^{\mathrm{a}, \mathrm{B}}$ & 0.16 & $<0.001^{*}$ \\
\hline 12 months & $6.09^{\mathrm{C}, \mathrm{E}}$ & 0.20 & $6.38^{\mathrm{b}, \mathrm{E}}$ & 0.20 & $6.79^{\mathrm{a}, \mathrm{A}}$ & 0.12 & $<0.001^{*}$ \\
\hline$p$ value & $<0.001^{*}$ & $<0.001^{*}$ & $<0.001^{*}$ & & & & \\
\hline
\end{tabular}

$\left(^{*}\right)$ : significant; (ns): nonsignificant. Statistical comparison between tested groups at $p \leq 0.05$. Different small-letter superscripts indicate statistically significant difference within the same row. Different capital-letter superscripts indicate statistically significant difference within the same column

Table 4: Oral side effects reported in group III (chlorhexidine)

\begin{tabular}{lllllll}
\hline & \multicolumn{4}{c}{ Oral side effects } \\
\cline { 2 - 6 } G3 $(\mathrm{CHX})$ & Taste disturbance & Burning sensation & Mucosal irritation & Metallic taste & Numbness & $\begin{array}{l}\text { Sore mouth } \\
\text { or tongue }\end{array}$ \\
\hline $\begin{array}{l}\text { Number of } \\
\text { participants (\%) }\end{array}$ & $7(54 \%)$ & $6(46 \%)$ & $4(31 \%)$ & $3(23 \%)$ & $2(15 \%)$ & $2(15 \%)$ \\
\hline
\end{tabular}

G3 $(p<0.05)$. Also, a statistically significant difference was found between $\mathrm{G} 2$ and $\mathrm{G} 3(p<0.05)$.

\section{Oral Side Effects}

Regarding G1 (Gum Arabic) and G2 (Licorice), no oral side effects were reported after using the mouthwashes. On the other hand, there were several oral side effects reported in G3 (Chlorhexidine).
In G3, a total of 13 out of 21 participants reported oral side effects (62\%). The most common reported side effects were taste disturbance (54\%) and burning sensation (46\%). This was followed by mucosal irritation (31\%) and metallic taste (23\%). Other reported side effects were numbness and sore mouth or tongue (15\%). Table 4 represents the oral side effects reported with chlorhexidine. 


\section{Discussion}

Dental caries is the most prevalent oral disease and represents a major public health problem worldwide. The caries process involves bacterial adherence to the tooth surfaces followed by the localized demineralization of dental hard tissue by acids produced from the bacterial fermentation of carbohydrates. The most related bacteria in its etiology are Streptococcus mutans, responsible for its onset, and Lactobacillus acidophilus, responsible for its advancement. ${ }^{38}$

Until today, the modern concepts of caries risk assessment signify microorganisms as one of the major etiological factors for dental caries. ${ }^{39}$ Prevention of the disease implements decreasing the levels of these cariogenic bacteria. ${ }^{15}$ Research in caries prevention has been adopting strategies entirely focused on reducing or eliminating cariogenic bacteria from the oral cavity. Studies reported that although caries can be prevented by regular toothbrushing and flossing, it is difficult to eliminate Streptococcus mutans from pits, fissures, and proximal surfaces by mechanical means alone. ${ }^{40}$ In order to reach effective caries control, these methods should be combined with chemoprophylactic agents. ${ }^{41}$

Thus, preventive dentistry urges the need to develop novel therapeutic protocols to minimize the cariogenic microbial load in the oral cavity. Oral rinses are a common tool employed to deliver such therapeutic ingredients to all surfaces of the mouth, including inaccessible areas. ${ }^{42}$ It has been proved that mouthwash is a simple and acceptable method to deliver antimicrobial agents into the oral cavity to act as an adjunct to the patient's oral hygiene measures. ${ }^{27}$

Mouthwashes have gained great popularity due to the fact that ideal plaque control solely by mechanical means requires significant effort and is difficult to achieve, which accordingly resulted in most individuals are unable to maintain adequate oral hygiene. ${ }^{43}$ In addition, mouth rinsing is well established as a safe and cost-efficient mass prophylactic method when compared to other caries preventive measures. ${ }^{9}$

Chlorhexidine has been considered the "gold standard" among different mouthwashes due to its broad-spectrum antimicrobial property. Chlorhexidine is a cationic bisbiguanide that results in membrane disruption of the bacteria, causing a concentrationdependent growth inhibition and cell death. ${ }^{44}$ However, its use has been reported to exhibit several undesirable side effects such as altered taste perception, burning sensation, metallic taste, staining of tongue and teeth, and restorations and emergence of bacterial resistance. ${ }^{45}$ Therefore, there is a continuous search for alternative antimicrobial products. This has led to a renewed interest in herbal medicine. Medicinal plants are well recognized as new antibacterial agents. They offer many advantages such as low cost, ease of availability, nontoxic nature, increased shelf life, and lack of microbial resistance. ${ }^{9}$ They also possess minimal side effects and hence can be used for daily prophylactic measures. Thus, they can be used as therapeutic substitutes for synthetic antimicrobial agents. ${ }^{10}$

Glycyrrhiza glabra, commonly known as Licorice, is a medicinal plant used by many cultures for thousands of years to relieve coughs, sore throats, and gastric ulcers. It has contributed to treating several diseases such as atherosclerosis, immunodeficiency, hepatitis, and bacterial infections. It has been used worldwide as a sweetener and a flavoring agent. The phytochemical analysis of Licorice extract revealed the presence of tannins, saponins, glycosides, and flavonoids, which contribute to its antibacterial activity. ${ }^{7}$ Glycyrrhizin is another main active compound in Licorice known to reduce bacterial growth and acid production. ${ }^{7}$ Due to its anti-adherence, antimicrobial, soothing, and anti-inflammatory properties, Licorice has been of great interest in dentistry. The beneficial effects of Licorice in oral diseases such as dental caries, gingivitis, periodontitis, aphthous ulcers, and oral cancer have been reported in various studies. ${ }^{46}$

Acacia gum, generally known as Gum Arabic, is a traditional herbal plant known for its cardiac, renal, gut, and dental protective effects. It possesses antimicrobial, anti-inflammatory, fungicide, and anti-coagulant properties. Phytochemical screening indicated that Acacia gum extracts contain alkaloids, saponins, cardiac glycosides, tannins, flavonoids, and anthraquinones, which are responsible for its antibacterial properties. ${ }^{47,48}$ It has been proven effective in the treatment of malaria, sore throat, toothache, acute diarrhea, bronchitis, bleeding hemorrhoids, and leukoderma. Also, studies reported that it has the ability to enhance tooth remineralization, because it contains high concentrations of calcium ions. ${ }^{12,49}$

Various in vitro studies reported that both Acacia gum and Licorice extracts possess antibacterial activity against Streptococcus mutans and Lactobacillus acidophilus. Despite the added benefits provided by herbal products when compared to chemical mouthwashes, there have been no clinical studies reported in the literature that compared their effects on caries prevention on long-term basis. Therefore, this study was conducted to evaluate the caries preventive effect, the antibacterial properties, and the prevalence of oral side effects of these two herbal mouthwashes compared to chlorhexidine in high caries-risk patients over a 12-month period.

Different studies proved that ethanolic-based crude extracts show higher antibacterial effect compared to aqueous extracts. This is due to alcohol being a better solvent (promote better solubility) than water. The polar nature of ethanol shows better dissolving capacity and results in leaching out more active ingredients during extraction. ${ }^{23}$ Therefore, ethanol solvent was used in this study. The solvent did not contribute to the antibacterial activity since it had been completely removed by lyophilization and freeze-dried extracts were delivered. ${ }^{7}$

Regarding the antibacterial effect, findings of this study revealed that the three mouthwashes showed significant antibacterial effect against Streptococcus mutans and Lactobacillus acidophilus after 3 and 6 months with no statistically significant difference between them. However, after 9 and 12 months, they showed different results. For Gum Arabic and Licorice, there was a time-dependent decrease in Streptococcus mutans and Lactobacillus acidophilus colony counts from baseline till after 12 months indicating a statistically significant prolonged (long-term) antibacterial effect. These findings are in agreement with studies done by Jain et al. ${ }^{7}$ and Öznurhan et al. ${ }^{41}$ who also found that Licorice mouthwash was effective in reducing Streptococcus mutans colony counts and showed antibacterial potential similar to chlorhexidine. Several in vitro studies also confirmed the antibacterial potential of Gum Arabic against Streptococcus mutans. ${ }^{11-13}$

For chlorhexidine, there was a significant reduction in colony counts after 3 and 6 months only. There was no statistically significant difference between 3 and 6 months' antibacterial effect. On the other hand, after 9 and 12 months, the Streptococcus mutans and Lactobacillus acidophilus colony counts increased indicating bacterial resistance. There was no statistically significant difference between baseline and 12 months' Lactobacillus acidophilus colony counts. These findings are in accordance with several in vitro studies done by Kulik et al., ${ }^{50}$ Wang et al., ${ }^{51}$ Kaspar et al., ${ }^{52}$ and a clinical 
study done by Jothika et al., ${ }^{44}$ where they also found an increase in colony counts and bacterial resistance against chlorhexidine after prolonged exposure. They recommended the use of chlorhexidine should be limited to short periods of time.

Regarding caries incidence, Gum Arabic and Licorice showed no significant increase in DMF scores after 3,6, and 9 months. Chlorhexidine showed no significant increase in DMF scores after 3 and 6 months only. However, there was no statistically significant difference between the three mouthwashes after 3, 6, and 9 months. After 12 months, there was a statistically significant difference between chlorhexidine and each of Gum Arabic and Licorice where chlorhexidine showed higher DMF scores compared to the other two natural mouthwashes. This indicates that Gum Arabic and Licorice mouthwashes may have more caries preventive potential than chlorhexidine as caries was prevented for a longer period and caries incidence occurred much less when compared to chlorhexidine. This may be attributed to their antibacterial potential that was effective even after 12 months, while chlorhexidine showed bacterial resistance that may have resulted in a higher caries incidence. This was in agreement with one study done by Tandon et al. ${ }^{53}$ that also assessed the effect of an herbal mouthwash vs chlorhexidine on the caries status for a period of 9 months. They found that there was no significant increase in the DMFS scores at the end of 9 months. Since this study lacks further evidence to support its findings, as most studies in the literature where either of short duration or did not assess the caries status, more research is necessary to confirm the effect of these mouthwashes on caries incidence and whether they play a role in caries prevention.

Regarding oral side effects, none was reported after using Gum Arabic and Licorice mouthwashes. This may be attributed to the fact that they are natural products and are considered safe and nontoxic. These results are in accordance with studies done by Almaz et al., ${ }^{5}$ Jain et al., ${ }^{7}$ and Gupta and Gupta ${ }^{54}$ where they also reported that no oral side effects occurred after the use of Acacia gum and Licorice products.

On the other hand, there were several oral side effects reported with chlorhexidine. The most common reported side effects were taste disturbance and burning sensation. Other reported side effects were mucosal irritation, metallic taste, numbness, and sore mouth or tongue. Chlorhexidine mouthwash reversibly alters taste sensation in a time-dependent manner. The taste is altered as bitter taste sensation increases, and salty taste is impaired. This is a result of epithelial ion transport-based interference of chlorhexidine with specific taste buds. The burning sensation and mucosal irritation might have stemmed from chlorhexidine itself or perhaps have arisen from other ingredients, as these side effects were also associated with alcohol-containing mouthwashes, yet reported to be lower with water-based mouthwashes. ${ }^{55}$ These findings are consistent with results of other studies, where side effects were also observed and reported by Guerra et al., ${ }^{36}$ Haydari et al., ${ }^{37}$ and Abdulkareem et al. ${ }^{55}$ and they concluded that the continuous use of chlorhexidine manifests undesirable side effects. Those undesirable side effects limit the long-term use and patient acceptability of chlorhexidine mouthwashes.

Limitations of this study include the continuous monitoring of participants' oral hygiene habits and the proper rinsing technique of mouthwashes. However, this is considered not be differential between the groups. Dietary parameters or an attempt to modify the participants' diet was also not taken into consideration, which might have affected the results.

\section{Conclusion}

Under the limitations of this clinical trial, it can be concluded that Gum Arabic and Licorice herbal mouthwashes show promising caries preventive and antibacterial effects. They can serve as substitutes to chemical agents such as chlorhexidine, providing effective caries control, antibacterial activity, and safe long-term use. These natural mouthwashes may be more beneficial and can be used daily as they are characterized by a nontoxic profile with no oral side effects.

\section{Clinical Significance}

Natural herbal extracts may help develop new therapeutic agents or strategies to prevent or control dental caries. They could be incorporated as an anti-caries agent in dental products such as mouthwashes or toothpastes. In the future, they may become an essential part of caries preventive programs. Further clinical studies are recommended to confirm these findings and to determine the proper therapy regimen such as the dose and duration of these natural herbs for effective caries prevention.

\section{References}

1. Cheng J, Chaffee BW, Cheng NF, et al. Understanding treatment effect mechanisms of the CAMBRA randomized trial in reducing caries increment. J Dent Res 2015;94(1):44-51. DOI: 10.1177/0022034514555365.

2. Pitts NB, Zero DT, Marsh PD, et al. Dental caries. Nat Rev Dis Primers 2017;3(1):17030. DOI: 10.1038/nrdp.2017.30.

3. Horst JA, Tanzer JM, Milgrom PM. Fluorides and other preventive strategies for tooth decay. Dent Clin North Am 2018;62(2):207-234. DOI: 10.1016/j.cden.2017.11.003.

4. Singhal R, Agarwal V, Rastogi P, et al. Efficacy of acacia arabica gum as an adjunct to scaling and root planing in the treatment of chronic periodontitis: a randomized controlled clinical trial. Saudi Dent J 2018;30(1):53-62. DOI: 10.1016/j.sdentj.2017.10.006.

5. Almaz ME, Sönmez IŞ, Ökte Z, et al. Efficacy of a sugar-free herbal lollipop for reducing salivary Streptococcus mutans levels: a randomized controlled trial. Clin Oral Investig 2017;21(3):839-845. DOI: 10.1007/s00784-016-1827-y.

6. Hambire CU, Jawade R, Patil A, et al. Comparing the antiplaque efficacy of $0.5 \%$ camellia sinensis extract, $0.05 \%$ sodium fluoride, and $0.2 \%$ chlorhexidine gluconate mouthwash in children. J Int Soc Prev Community Dent 2015;5(3):218-226. DOI: 10.4103/2231-0762.158016.

7. Jain E, Pandey RK, Khanna R. Liquorice root extracts as potent cariostatic agents in pediatric practice. J Indian Soc Pedod Prev Dent 2013;31(3):146-152. DOI: 10.4103/0970-4388.117964.

8. James P, Worthington HV, Parnell C, et al. Chlorhexidine mouthrinse as an adjunctive treatment for gingival health. Cochrane Database Syst Rev 2017;3:CD008676. DOI: 10.1002/14651858.CD008676.pub2.

9. Somaraj V, Shenoy RP, Shenoy PG, et al. Effect of herbal and fluoride mouth rinses on Streptococcus mutans and dental caries among 12-15-year-old school children: a randomized controlled trial. Int J Dent 2017;2017:5654373. DOI: 10.1155/2017/5654373.

10. Krishnakumar G, Gaviappa D, Guruswamy S. Anticaries efficacy of liquorice lollipop: an ex vivo study. J Contemp Dent Pract 2018;19(8):937-942. DOI: 10.5005/jp-journals-10024-2361.

11. Rao DS, Penmatsa T, Kumar AK, et al. Antibacterial activity of aqueous extracts of Indian chewing sticks on dental plaque: an in vitro study. J Pharm Bioallied Sci 2014;6(Suppl 1):S140-S145. DOI: 10.4103/09757406.137426

12. Banjar MM, Khafaji AM, Maher YA. Antimicrobial activity of hydrogen peroxide, sesame and gum Arabic against Streptococcus mutans. Int J Health Sci Res 2017;7(1):97-104. 
13. Khan MN, Ngassapa O, Matee MI. Antimicrobial activity of Tanzanian chewing sticks against oral pathogenic microbes. Pharm Biol 2000;38(3):235-240. DOI: 10.1076/1388-0209(200007)3831-sft235.

14. Jain I, Jain P. Comparative evaluation of antimicrobial efficacy of three different formulations of mouth rinses with multi-herbal mouth rinse. J Indian Soc Pedod Prev Dent 2016;34(4):315-323. DOI: 10.4103/09704388.191409.

15. PeRala SR, Bhupathiraju P. Efficacy of four fluoride mouth rinses on Streptococcus mutans in high caries risk children-a randomized controlled trial. J Clin Diagn Res 2016;10(9):ZC56-ZC60. DOI: 10.7860/ JCDR/2016/16107.8508.

16. Vadhana VC, Sharath A, Geethapriya PR, et al. Effect of sesame oil, ozonated sesame oil, and chlorhexidine mouthwash on oral health status of adolescents: a randomized controlled pilot trial. J Indian Soc Pedod Prev Dent 2019;37(4):365-371. DOI: 10.4103/JISPPD. JISPPD_244_19.

17. Polizzi E, Tetè G, Bova F, et al. Antibacterial properties and side effects of chlorhexidine-based mouthwashes. A prospective, randomized clinical study. J Osseointegr 2020;12(1):2-7. DOI: 10.23805/ JO.2019.12.01.20.

18. Patil RU, Dastoor PP, Unde MP. Comparative evaluation of antimicrobial effectiveness of probiotic milk and fluoride mouthrinse on salivary Streptococcus mutans counts and plaque scores in children-an in vivo experimental study. J Indian Soc Pedod Prev Dent 2019;37(4):378-382. DOI: 10.4103/JISPPD.JISPPD_45_19.

19. Qudeimat MA, Altarakemah $\mathrm{Y}$, Alomari $\mathrm{Q}$, et al. The impact of ICDAS on occlusal caries treatment recommendations for high caries risk patients: an in vitro study. BMC Oral Health 2019;19(1):41. DOI: 10.1186/ s12903-019-0730-8.

20. Li R, Lo EC, Liu BY, et al. Randomized clinical trial on preventing root caries among community-dwelling elders. JDR Clin Trans Res 2017;2(1):66-72. DOI: 10.1177/2380084416668491.

21. Mitchell JK, Brackett MG, Haywood VB. Strategies to avoid underdiagnosing pit-and-fissure caries. Compend Contin Educ Dent 2018;39(2):79-83.

22. Oliveira BH, Salazar M, Carvalho DM, et al. Biannual fluoride varnish applications and caries incidence in preschoolers: a 24-month follow-up randomized placebo-controlled clinical trial. Caries Res 2014;48(3):228-236. DOI: 10.1159/000356863.

23. Sedighinia F, Afshar AS. Antibacterial activity of Glycyrrhiza glabra against oral pathogens: an in vitro study. Avicenna J Phytomed 2012;2(3):118-124.

24. Haghgoo R, Mehran M, Zadeh HF, et al. Comparison between antibacterial effect of chlorhexidine $0.2 \%$ and different concentrations of Cyperus rotundus extract: an in vitro study. J Int Soc Prev Community Dent 2017;7(5):242-246. DOI: 10.4103/jispcd.JISPCD_157_17.

25. Akhlaghi N, Sadeghi M, Fazeli F, et al. The antibacterial effects of coffee extract, chlorhexidine, and fluoride against Streptococcus mutans and Lactobacillus plantarum: an in vitro study. Dent Res J (Isfahan) 2019;16(5):346-353. DOI: 10.4103/1735-3327.266093.

26. Elgamily H, Safy R, Makharita R. Influence of medicinal plant extracts on the growth of oral pathogens Streptococcus mutans and Lactobacillus acidophilus: an in-vitro study. Open Access Maced J Med Sci 2019;7(14):2328-2334. DOI: 10.3889/oamjms.2019.653.

27. Hu C, He J, Eckert R, et al. Development and evaluation of a safe and effective sugar-free herbal lollipop that kills cavity-causing bacteria. Int J Oral Sci 2011;3(1):13-20. DOI: 10.4248/IJOS11005.

28. Okoro SO, Kawo AH, Arzai AH. Phytochemical screening, antibacterial and toxicological activities of acacia senegal extracts. Bayero J Pure Appl Sci 2012;5(1):163-170. DOI: 10.4314/bajopas.v5i1.29.

29. Al Alawi SM, Hossain MA, Abusham AA. Antimicrobial and cytotoxic comparative study of different extracts of Omani and Sudanese gum acacia. Beni-Suef Uni J Basic Appl Sci 2018;7(1):22-26. DOI: 10.1016/j. bjbas.2017.10.007.

30. Megalaa N, Thirumurugan K, Kayalvizhi G, et al. A comparative evaluation of the anticaries efficacy of herbal extracts (tulsi and black myrobalans) and sodium fluoride as mouthrinses in children: a randomized controlled trial. Indian J Dent Res 2018;29(6):760-767. DOI: 10.4103/ijdr.IJDR_790_16.

31. Salama MT, Alsughier ZA. Effect of green tea extract mouthwash on salivary Streptococcus mutans counts in a group of preschool children: an in vivo study. Int J Clin Pediatr Dent 2019;12(2):133-138. DOI: 10.5005/jp-journals-10005-1610.

32. Ravindran S, Chaudhary M, Gawande M. Enumeration of salivary streptococci and lactobacilli in children with differing caries experiences in a rural Indian population. ISRN Plast Surg 2013;2013:476783. DOI: 10.5402/2013/476783.

33. Al-Jumaily EF, AL-Seubehawy HM, Al-Toraihy FA. Isolation and identification of Streptococcus mutans (H5) produced glucosyltransferase and cell-associated glucosyltransferase isolated from dental caries. Int J Curr Microbiol App Sci 2014;3(6):850-864.

34. Shah S, Bargale S, Dave BH, et al. Comparison of antimicrobial efficacy of (between) $0.2 \%$ chlorhexidine and herbal mouthwash on salivary Streptococcus mutans: a randomized controlled pilot study. Contemp Clin Dent 2018;9(3):440-445. DOI: 10.4103/ccd.ccd_264_18.

35. Moini P, Eslami G, Taheri S, et al. In vitro comparative evaluation of the antibacterial efficacy of licorice aqueous root extract (Glycyrrhiza glabra) and chlorhexidine against Lactobacillus acidophilus. J Res Dentomaxillofac Sci 2016;1(2):7-14. DOI: 10.29252/jrdms.1.2.7.

36. Guerra F, Pasqualotto D, Rinaldo F, et al. Therapeutic efficacy of chlorhexidine-based mouthwashes and its adverse events: performance-related evaluation of mouthwashes added with antidiscoloration system and cetylpyridinium chloride. Int J Dent Hyg 2019;17(3):229-236. DOI: 10.1111/idh.12371.

37. Haydari M, Bardakci AG, Koldsland OC, et al. Comparing the effect of $0.06 \%-, 0.12 \%$ and $0.2 \%$ chlorhexidine on plaque, bleeding and side effects in an experimental gingivitis model: a parallel group, double masked randomized clinical trial. BMC Oral Health 2017;17(1):118. DOI: 10.1186/s12903-017-0400-7.

38. Thomas A, Thakur S, Habib R. Comparison of antimicrobial efficacy of green tea, garlic with lime, and sodium fluoride mouth rinses against Streptococcus mutans, Lactobacilli species, and Candida albicans in children: a randomized double-blind controlled clinical trial. Int J Clin Pediatr Dent 2017;10(3):234-239. DOI: 10.5005/ jp-journals-10005-1442.

39. Ajagannanavar $\mathrm{SL}$, Battur $\mathrm{H}$, Shamarao $\mathrm{S}$, et al. Effect of aqueous and alcoholic licorice (Glycyrrhiza glabra) root extract against Streptococcus mutans and Lactobacillus acidophilus in comparison to chlorhexidine: an in vitro study. J Int Oral Health 2014;6(4):29-34.

40. Bafna H, Ajithkrishnan C, Kalantharakath T, et al. Effect of short-term consumption of amul probiotic yogurt containing Lactobacillus acidophilus La5 and bifidobacterium lactis $\mathrm{Bb} 12$ on salivary Streptococcus mutans count in high caries risk individuals. Int J Appl Basic Med Res 2018;8(2):111-115.DOI: 10.4103/ijabmr.IJABMR_447_16.

41. Öznurhan F, Buldur B, Cartı Ö, et al. Antimicrobial efficacy of chlorhexidine and licorice mouthwashes in children. Meandros Med Dent J 2019;20(1):13-19. DOI: 10.4274/meandros.galenos.2018.79663.

42. Sharma A, Agarwal N, Anand A, et al. To compare the effectiveness of different mouthrinses on Streptococcus mutans count in caries active children. J Oral Biol Craniofac Res 2018;8(2):113-117. DOI: 10.1016/j. jobcr.2018.05.002.

43. Tadakamadla SK, Bharathwaj VV, Duraiswamy P, et al. Clinical efficacy of a new cetylpyridinium chloride-hyaluronic acid-based mouthrinse compared to chlorhexidine and placebo mouthrinses-A 21-day randomized clinical trial. Int J Dent Hyg 2020;18(1):116-123. DOI: 10.1111/idh.12413.

44. Jothika M, Vanajassun PP, Someshwar B. Effectiveness of probiotic, chlorhexidine and fluoride mouthwash against Streptococcus mutans-randomized, single-blind, in vivo study. J Int Soc Prev Community Dent 2015;5(Suppl 1):S44-S48. DOI: 10.4103/22310762.156153 .

45. Mitra D, Yadav A, Prithyani S, et al. The antiplaque efficacy of lantibiotic Nisin extract mouthrinse. J Indian Soc Periodontol 2019;23(1):31-34. DOI: 10.4103/jisp.jisp_326_18. 
46. Sidhu P, Shankargouda S, Rath A, et al. Therapeutic benefits of liquorice in dentistry. J Ayurveda Integr Med 2020;11(1):82-88. DOI: 10.1016/j.jaim.2017.12.004.

47. Magnini RD, Hilou A, Millogo-Koné $H$, et al. Acacia senegal extract rejuvenates the activity of phenicols on selected enterobacteriaceae multi drug resistant strains. Antibiotics (Basel) 2020;9(6):323. DOI: 10.3390/antibiotics9060323.

48. Patel S, Goyal A. Applications of natural polymer gum arabic: a review. Int J Food Prop 2015;18(5):986-998. DOI: 10.1080/10942912.2013. 809541.

49. Paramita N, Soufyan A, Irawan B, et al. Effect of gum arabic (Acacia senegal) topical gel application on demineralized enamel hardness. J Phys Conf Ser 2018;1073(3):032016. DOI: 10.1088/17426596/1073/3/032016

50. Kulik EM, Waltimo T, Weiger R, et al. Development of resistance of mutans streptococci and Porphyromonas gingivalis to chlorhexidine digluconate and amine fluoride/stannous fluoride-containing mouthrinses, in vitro. Clin Oral Investig 2015;19(6):1547-1553. DOI: 10.1007/s00784-014-1379-y.
51. Wang S, Zhou C, Ren B, et al. Formation of persisters in Streptococcus mutans biofilms induced by antibacterial dental monomer. J Mater Sci Mater Med 2017;28(11):178. DOI: 10.1007/s10856-017-5981-9.

52. Kaspar JR, Godwin MJ, Velsko IM, et al. Spontaneously arising Streptococcus mutans variants with reduced susceptibility to chlorhexidine display genetic defects and diminished fitness. Antimicrob Agents Chemother 2019;63(7):e00161-19. DOI: 10.1128/ AAC.00161-19.

53. Tandon S, Gupta K, Rao S, et al. Effect of triphala mouthwash on the caries status. Int J Ayurveda Res 2010;1(2):93-99. DOI: 10.4103/09747788.64413.

54. Gupta D, Gupta RK. Investigation of antibacterial efficacy of Acacia nilotica against salivary mutans streptococci: a randomized control trial. Gen Dent 2015;63(1):23-27.

55. Abdulkareem AA, Al Marah ZA, Abdulbaqi HR, et al. A randomized double-blind clinical trial to evaluate the efficacy of chlorhexidine, antioxidant, and hyaluronic acid mouthwashes in the management of biofilm-induced gingivitis. Int J Dent Hyg 2020;18(3):268-277. DOI: 10.1111/idh.12432. 